\title{
Erratum to: The Infrared Solar Spectrum Measured by the SOLSPEC Spectrometer Onboard the International Space Station
}

\section{G. Thuillier ${ }^{1}$ J.W. Harder ${ }^{2}$ - A. Shapiro ${ }^{3}$ - T.N. Woods ${ }^{2}$. J.-M. Perrin ${ }^{4}$ - M. Snow ${ }^{2}$ - T. Sukhodolov ${ }^{5}$ W. Schmutz ${ }^{5}$}

Published online: 19 October 2015

(C) Springer Science+Business Media Dordrecht 2015

Erratum to: Solar Phys (2015) 290: 1581-1600

DOI 10.1007/s11207-015-0704-1

In the recently published article the affiliation of two authors was in error. Please note that the correct address of T. Sukhodolov and W. Schmutz is:

Physikalisch-Meteorologisches Observatorium Davos, World Radiation Center, 7260 Davos Dorf, Switzerland.

The online version of the original article can be found under doi:10.1007/s11207-015-0704-1.

\section{G. Thuillier}

gerard.thuillier@latmos.ipsl.fr

1 LATMOS-CNRS, 11 blvd d'Alembert, 78280 Guyancourt, France

2 Laboratory for Atmospheric and Space Physics, University of Colorado, 3665 Discovery Drive, Boulder, CO 80303, USA

3 Max-Planck Institut, Gottingen, Germany

4 Observatoire de Haute-Provence du CNRS, 04870 Saint Michel l'Observatoire, France

5 Physikalisch-Meteorologisches Observatorium Davos, World Radiation Center, 7260 Davos Dorf, Switzerland 